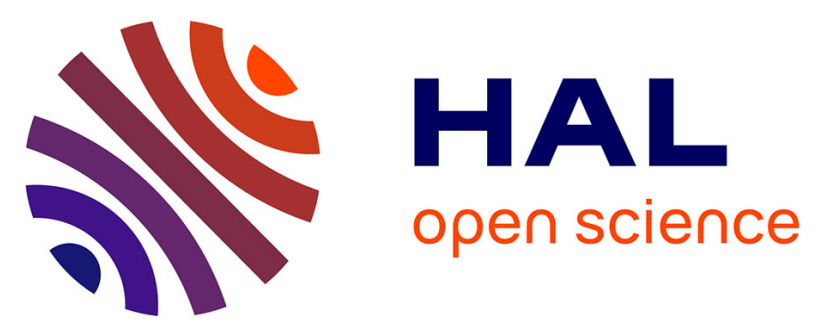

\title{
Prescription patterns of first- and second-generation antipsychotic drugs in the French population
}

Viviane Kovess-Masféty, Frédéric Balusson, Emmanuelle Leray, Mathilde Husky, Lucie-Marie Scailteux

\section{- To cite this version:}

Viviane Kovess-Masféty, Frédéric Balusson, Emmanuelle Leray, Mathilde Husky, Lucie-Marie Scailteux. Prescription patterns of first- and second-generation antipsychotic drugs in the French population. Fundamental \& Clinical Pharmacology, 2020, 34 (5), pp.603-611. 10.1111/fcp.12553 . hal02534802

HAL Id: hal-02534802

https://hal-univ-rennes1.archives-ouvertes.fr/hal-02534802

Submitted on 4 May 2020

HAL is a multi-disciplinary open access archive for the deposit and dissemination of scientific research documents, whether they are published or not. The documents may come from teaching and research institutions in France or abroad, or from public or private research centers.
L'archive ouverte pluridisciplinaire HAL, est destinée au dépôt et à la diffusion de documents scientifiques de niveau recherche, publiés ou non, émanant des établissements d'enseignement et de recherche français ou étrangers, des laboratoires publics ou privés. 
PROF. VIVIANE KOVESS-MASFETY (Orcid ID : 0000-0001-7045-6175)

DR. LUCIE-MARIE SCAILTEUX (Orcid ID : 0000-0001-7047-9107)

Article type : Original Article

\title{
Prescription patterns of first- and second-generation antipsychotic drugs in the French population
}

Running title: FGAP and SGAP Prescriptions in France

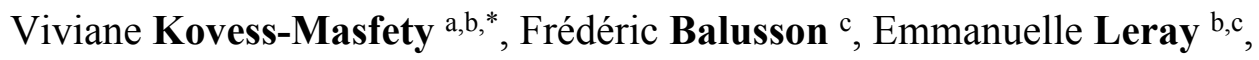 \\ Mathilde Husky ${ }^{d}$, Lucie-Marie Scailteux ${ }^{\text {e }}$
}

a EHESP School for Public Health, Dpt Health Epidemiology and biostatistics for decision making in public health, Rennes, France

${ }^{\mathrm{b}}$ EA4057 Institut de psychologie, Université Paris Descartes, France

c Université de Rennes, EA 7449 REPERES, Pharmacoepidemiology and Health Services Research, 35000 Rennes, France

d Université de Bordeaux, Laboratoire de Psychologie EA4139, Bordeaux, France

e Centre Régional de Pharmacovigilance, de Pharmaco-épidémiologie et d'information sur le médicament, CHU de Rennes, France

This article has been accepted for publication and undergone full peer review but has not been through the copyediting, typesetting, pagination and proofreading process, which may lead to differences between this version and the Version of Record. Please cite this article as doi: $\underline{10.1111 / F C P .12553}$ 
*Corresponding author

Viviane Kovess-Masfety

vkovess@gmail.com 


\section{ABSTRACT}

This study assessed in depth the use of first- and second-generation antipsychotic (FGAP/SGAP) drugs in France.

A 1/97th random sample of beneficiaries affiliated to the French Health Insurance system Echantillon Généraliste des Bénéficiaires (EGB) - was used: a) 621,662 persons in 2015 among which 11,319 had an antipsychotic (AP) prescription; b) a sample of first AP prescriptions concerning 5,935 patients in 2013 and 2014 (no AP in the last six months of 2012) for whom diagnostic was available in $40 \%$ of cases.

In 2015, AP prevalence was 21.9/1000. SGAP/FGAP ratio was 1.02. Long-lasting prescriptions were rare: 1.79/1000 for FGAP and 1.38/1000 for SGAP. FGAP first prescriptions were higher than SGAP for each age class, except for $<18$ aged patients; $2.85 \%$ had both generations; $50.7 \%$ of the patients had another psychotropic. GPs prescribed more FGAPs than SGAPs, psychiatrists prescribed more SGAPs and hospital-based practitioners prescribed both generations equally, and these patterns changed across age ranges: for the elderly, GPs are the more frequent prescribers. SGAP/FGAP ratio is different by diagnostic categories.

In France, FGAPs are largely prescribed by GPs mainly for the elderly but young and adult patients are concerned as well. Inappropriate antipsychotic consumption through off-label use, which adds to the co-prescription, especially in vulnerable population groups, mainly concerns FGAP prescriptions by GPs who do not have psychiatric training and limited contact with psychiatrists. Attention should then be brought to the regulatory advisory agencies in order to better inform and train the prescribers. 


\section{INTRODUCTION}

Between 1985 and 1994, overall psychotropic medication prescriptions were reported to have dramatically increased in the U.S. [1], though the trend was not observed for antipsychotic (AP) medications. However, in the mid-1990s' the introduction of second-generation antipsychotic medications (SGAPs), launched with the promise of inducing fewer side effects as compared to the first-generation antipsychotics (FGAPs), brought in an increase in AP prescriptions largely attributed to these new drugs [2]. In addition, lowering the risk of side effects [3] may have favored compliance and treatment duration, de facto increasing their use. Moreover, an extension of approved indications obtained for several SGAPs, in particular in the treatment of bipolar disorder in adults [2], together with an inflation of bipolar disorder diagnoses [4] certainly contributed to that increase. Furthermore, it has been suggested that a key contributor may have been a rise in off-label prescriptions of SGAPs mainly in both extremes of the age spectrum: i) prescribing to young people for behavioral disorders [5] and ii) prescribing to elderly people for dementia or organic mental disorders $[6,7]$.

A meta-analysis of general population samples from 16 countries confirmed a global increase of AP prescriptions from 2005 to 2014, mainly due to a rise of SGAP prescriptions [8]. This study by O. Halfdanarson et al. further showed a heterogeneous evolution of AP use with increases in 10 of the 16 studied countries and decreases in five countries. The same study also showed large between-country differences regarding prescriptions reflected by an atypical/typical ratio ranging from 0.7 (Taiwan) to 6.1 (New Zealand and Australia) [8]. In this study, France had one of the lowest SGAP/FGAP ratios (1.1). These findings are consistent with a previous study by G. Désaméricq et al. based on a 2010 French national database [9] that showed how in France, APs were often prescribed off-label for long durations, especially among elderly persons without any diagnosed psychiatric disorder. Furthermore, at the other end of the age spectrum, another study on a French database showed stable first prescription rates among 0-25 year-olds over the 2006-2013 period with a decrease of FGAPs while SGAPs increased [10].

Thus, France appears to have some particularities, regarding its SGAP versus FGAP use, which deserve attention. The present study aims at providing a detailed description of FGAP and SGAP prescriptions; i.e., prescription forms, which prescribers according to the age group to whom the APs were prescribed, as well as concomitant reimbursement with other psychotropic drugs, and whenever information was available, the diagnostic profile of the patients. 


\section{METHODS}

The Echantillon Généraliste de Bénéficiaires (EGB) database was used. The EGB covers a 1/97th representative sample of the beneficiaries affiliated with the French Health Insurance system whether they received healthcare reimbursements or not [11]. The EGB contains anonymous information on basic sociodemographic characteristics and detailed medical data including medical acts, pharmacy dispensations, reasons for hospitalization, and related medical costs.

In the calendar year 2015, the EGB covered 621,662 beneficiaries with various insurance policies (hired workers, students, farmers, and others). The database provided detailed information with regard to medication reimbursements: name and form of the drug, prescription date, type of prescriber, and basic sociodemographic information. The 2015 EGB is representative of the national population regarding age, gender, occupation and medical expenses [11]. Data were analyzed in two samples: i) the total dispensations of APs for the year 2015 ( $\mathrm{N}=11,319$ persons); ii) the first dispensations of APs within the 2013-2014 period ( $N=5,935$ persons). Among the patients to whom APs were prescribed, a psychiatric diagnostic was identified because they benefitted from a special allowance for long-term illness "Affection Longue Durée" (ALD) which allowed a $100 \%$ reimbursement of all disease-related claims during our observation period.

Claims for reimbursement of drugs were classified according to the WHO anatomical therapeutic chemical (ATC) classification system as follows:

(1) FGAP: chlorpromazine, cyamemazine, droperidol, flupentixol, fluphenazine, haloperidol, levomepromazine, loxapine, penfluridol, periciazine, perphenazine, pimozide, pipamperone, pipotiazine, sulpiride, tiaprid, zuclopenthixol;

(2) SGAP: amisulpride, aripiprazole, clozapine, olanzapine, paliperidone, risperidone, quetiapine.

The following outcomes were considered:

1) the prevalence of FGAP and SGAP dispensations: defined by the proportion of patients with at least one AP dispensation in 2015; and the description of the form prescribed (oral short action versus long-lasting injection); 
2) the initial AP prescription (generation and specific type of AP drug) prescribed in the 20132014 period, defined as a prescription for a person who did not have a prescription for an AP in the previous two years (2011-2012);

3 ) the co-prescription either between AP generation, between AP and other psychotropic drugs in the 2013-2014 period; a co-prescription referred to a concomitant reimbursement of AP drugs with other AP or psychotropic drugs from the same prescription (at the same time);

4) the type of prescriber for each of AP drug at initial AP prescription in the 2013-2014 period;

5) the AP generation diagnostic profile for those who benefitted from ALD allowance.

In the 2015 data we referred to age ranges from 0 to $<20 ;=>20$ to $<65$ and $=>65$ because we wanted to compare the results to a recent international study on prevalence of AP generation prescriptions. For the first prescription sample, we kept using the widely WHO definition of children that is below 18 .

Analyses were conducted using SAS Guide Entreprise 7.1. T-tests were used to compare means and chi square tests were used to compare percentages.

\section{RESULTS}

\section{Prevalence of dispensations in the previous 12 months (2015)}

In the year 2015, 21.9/1000 of the French population received a least one AP: 21.3 for males, 22.4 for females (sex ratio $=0.95$ ). This rate widely varied depending on age: $4.1 / 1000$ for patients $<20$ years as opposed to $38.5 / 1000$ for patients $\geq 65$ years. Overall, 9.0/1000 received a FGAP only, 9.20 a SGAP only and 3.70 received both during the same year, yielding a SGAP/FGAP ratio of 1.02. Figure 1 illustrates a higher FGAP rate as compared to SGAPs for patients $\geq 65$ years in both sexes, and the opposite in younger groups.

For FGAPs, the oral form is by far the most prescribed: 8.2/1000 oral, 0.41 long-lasting, plus 0.41 for both, totaling 0.82 . For SGAPs, the trend is similar: $8.71 / 1000$ oral, $0.33 / 1000$ longlasting, plus $0.16 / 1000$ both, totaling $0.49 / 1000$. In addition, those who were using both longlasting AP generations in the same year should be included, thus adding 0.64/1000 to each 
generation. These rates were calculated on the total population, when in fact long-lasting prescriptions concerned adults only, increasing slightly the rates on adults, thus reaching 1.79/1000 for long-lasting FGAP and 1.38/1000 for SGAP as yearly prevalence for 2015. These long-lasting prescriptions are concentrated in the 30 to 60 year-old patients, where they reach $20 \%$ of AP prescriptions (figure 2).

Generation and type of AP drug prescribed as an initial AP prescription during the 2013 to 2014 period by age group $(\mathrm{N}=5,935)$.

For the first prescription, FGAPs represent $58 \%$, SGAPs $39 \%$ and both generations $2.8 \%$. Children (defined as below 18 years) have a different pattern: SGAP is the highest $53.8 \%$ versus $43 \%$ FGAP. Prescription profile for the elderly is very much the same as for adults except for both generations which are quite rare $0.9 \%$. Patterns by gender are quite similar: for women FGAP is $57.7 \%$ versus $58.3 \%$ for men; SGAP $40.1 \%$ for women versus $38 \%$ for men, and both AP generation prescriptions are slightly higher in men: 3.6 versus 2.2 for women.

\section{Insert Table 1 here}

In the total population, the FGAP Cyamemazine was the AP most commonly initiated (22.5\%), closely followed by the SGAP Risperidone (21.4\%), and Tiapride ranked third (11.3\%).

\section{Insert Table 2 here}

\section{Co-prescriptions}

In addition to the $2.9 \%$ who got both $\mathrm{AP}$ generations at initiation, another psychotropic drug was frequently (50.7\%) concomitantly prescribed: $47.9 \%$ of those who received a FGAP, $53.6 \%$ a 
SGAP, and $68 \%$ of those who had both generations. The differences between generations are significant $(>0.001)$.

Overall, 26.4\% have one additional prescription, $15.4 \%$ two, $7.1 \%$ three. Table 3 illustrates the number of prescriptions with concomitant reimbursement of non-AP psychotropic drugs, by generation: these percentages are higher for SGAP. Lastly, $43 \%$ of these psychotropic drugs are psychoanaleptics and 56.9\% psycholeptics; lithium concerns 23 patients only.

\section{Type of prescriber of the first AP prescription (between 2013 and 2014)}

There were important differences in the types of prescribers depending on the AP prescribed. Among the total AP prescriptions, GPs prescribed significantly more FGAPs (69.3\%) than SGAPs $(29.8 \%)$ and rarely both (1\%). Conversely, psychiatrists prescribed more SGAPs $(56.7 \%)$ versus FGAPs (40\%), and 3.3\% for both. Hospital-based practitioners had more balanced rates by generation: $49.4 \%$ for FGAPs versus $44.8 \%$ for SGAPs and $5.9 \%$ both. The differences in FGAP versus SGAP prescriptions varied significantly by type of prescribers $(p<.0001)$. Without consideration of the type of AP generation, GPs prescribed $47.8 \%$ of the total of APs, hospitalbased prescriptions accounted for $27.9 \%$ and psychiatrists $18.2 \%$.

In addition, prescriber patterns differed across patient age groups. Among youth $(<18$ years), AP prescribers were mostly hospital practitioners $(54.4 \%)$ followed by psychiatrists (20.3\%), and GPs (19.3\%). In contrast, among the elderly ( $\geq 65$ years), $66.2 \%$ of APs were prescribed by GPs, $20.2 \%$ by hospital-based practitioners and $6.9 \%$ only by psychiatrists $(\mathrm{p}<.0001)$. Overall, the youngest age group was the only group that received more SGAPs than FGAPs (53.8\% versus 43.3\%), while older patients received more FGAPs (59.5\%) than SGAPs (39.5\%) with significant differences in AP generation by age group $(\mathrm{p}<.0001)$.

Insert Table 4 here

\section{Antipsychotic generation prescriptions by diagnosis}


Among patients with a first AP prescription, 41.4\% $(n=2,458)$ had an ALD allowance that could be related to psychiatric diagnosis. Since some psychiatric diagnoses were too rare to be pooled (203 cases), we exploited eight main diagnostic categories. In these 2,255 ALD cases, 33.9\% were classified as depressed (excluding bipolar), 29.5\% as dementia, 11.4\% as schizophrenia or other psychoses, $10 \%$ bipolar disorder and $6 \%$ substance use disorder.

FGAPs and SGAPs were compared for each category, most of them showing significant differences: for substance use disorders, non-bipolar depression and anxiety, FGAPs were quantitatively more prescribed than SGAPs. Conversely for schizophrenia, bipolar disorder, mental retardation, dementia and autism, SGAPs were more prescribed than FGAPs.

Insert Table 5 here

\section{DISCUSSION}

This study confirms that the SGAP/FGAP prevalence ratio (1.02) is quite low in France as compared to what has been reported in other countries [8,12], though it is fairly close to what has been reported in Germany or Norway. In France, FGAPs remain frequently prescribed including for a first prescription and for shorter periods as compared to SGAPs. FGAPs are prescribed mainly to the elderly and to a lesser extent to younger age groups. This may be explained by the prescribers' preferences as suggested in France/U.S.A. comparisons [12].

Despite positive effects on compliance, the prescription of long-lasting forms is still quite low although the rate for SGAPs is now slightly higher than in a previous publication and since quite few patients received FGAPs and SGAPs in the same year, a substitution trend from the first generation of APs to the second may be occurring [13,14].

SGAP treatments seem to be initiated by mental health specialists such as private psychiatrists or hospital-based practitioners who are mainly psychiatrists. Hospital practitioners are the main prescribers of SGAPs for youths and it likely corresponds to their first psychotic episode as SGAPs are recommended as the first choice by the national health authority [15].

On the other hand, GPs mainly prescribe FGAPs to adults and to elderly patients. We observed that the age corresponds to different prescribers' patterns. Indeed, the prescriptions from 
GPs for adults and the elderly do not seem to be fully targeted towards patients suffering from psychiatric disorders as previously reported in a 2010 extraction of the EGB database [9]. In this latter study, the authors used diagnostic codes available for patients with long-term and chronic disease (ALD allowance) - including the most severe psychiatric disorders - and found that as much as $20 \%$ of the population aged 65 or older and $23 \%$ of the $15-65$ year-olds were prescribed APs without any psychiatric diagnosis, thus considered as off-label prescriptions. Using the same technique, the present findings confirm that among the 881 elderly persons receiving APs and for whom diagnostic information was available, $73.8 \%$ suffered from dementia; to a lesser extent, the same remark applied to children with autism (33.9\%) and/or mental retardation (14.5\%), and who received APs. However, for these children, contrarily to what happened with elderly people, the prescriptions were mostly initiated at the hospital or by psychiatrists or neurologists and not by GPs.

For the total population to whom APs were prescribed it appears as though SGAPs were perceived as the treatment of choice for private or hospital psychiatrists but not for GPs. In recent years French GPs have been strongly warned by the national health authority that anxiolytics, mainly benzodiazepines, should not be prescribed over long periods of time in particular to the elderly, which has led GPs to turn to AP drugs in the treatment of agitation and behavioral disorders in this population [16]. Moreover, it would appear that in France GPs are more familiar with FGAPs than with SGAPs which they may perceive as an AP for specialists. In addition, the main journal read by GPs in France, "Prescrire", has launched a number of warnings against SGAPs [17] and has described them as potentially dangerous due to side effects. On the other hand, FGAPs are seen as safer and equivalent in terms of quality of life compared to SGAPs [18]. In the present study, results show that the HAS guidelines regarding AP use in elderly populations are not followed, which raises serious public health concerns.

The AP drugs prescribed in France are somewhat different from those prescribed in several other countries: in the large cross-country comparisons mentioned previously, France was the only country where Cyamemazine, a FGAP, was the most prescribed drug followed by Risperidone, a SGAP which is the first prescribed drug in many other countries [8]. Quietapine which is also a frequent first rank prescription is not very high $5.2 \%$ (ranked $7^{\text {th }}$ ) preceded by Aripiprazole (5.4\%) and followed by Olanzapine $(5.0 \%)$ which are still below Sulpiride (ranked $4^{\text {th }}$ ) and Haloperidol (ranked $5^{\text {th }}$ ), both FGAPs, rarely reaching such high rankings in other countries [8]. Importantly, Cyamemazine is only authorized in France and Portugal [19]. It is manufactured by 
Sanofi Aventis France and raises the question of the influence of the pharmaceutical industry on prescriptions patterns. Indeed, France used to have a tradition of visits by medical representatives of pharmaceutical companies to the GPs and hospital practitioners in order to present and encourage the use of their products oftentimes accompanied by material benefits such a gifts, or financial support to attend conferences. This practice was largely criticized and since 2004 actions have been taken, so as to bring the information delivered by those representatives closer to scientific standards through more appropriate training, a strict banning of financial incentives, and the signature of a recently amended chart engaging the pharmaceutical industry to deliver best practice information for any drug they are promoting [20].

Curiously, the cost of APs and the fact that SGAPs are significantly more expensive than FGAPs have never been used as an argument against their usage. Indeed, the French health coverage allows for the reimbursement of such prescribed medications; especially as suffering a psychiatric disorder is considered as a long-term disease that gives right to free medication and care for all (ALD allowance). In the context of hospitals, this is different since the financial strains are prominent, and in psychiatry the cost of drugs, such as SGAPs, has dramatically increased although medication costs remain marginal compared to personnel-related costs.

In addition, an important number of French private psychiatrists are 60 years old or older [21] and were trained in medical schools to use FGAPs and are not convinced of the SGAPs' advantages. For older psychiatrists and for GPs, SGAPs not only failed to avoid known side effects but were also associated with serious adverse effects themselves (sometimes even more dangerous than the known side effects of FGAPs). As a consequence, few psychiatrists trained in the 70's prescribe SGAPs, except for young patients for whom there are clear recommendations.

Another finding is the high prevalence of co-prescriptions, not so much between APs but with other psychotropic drugs: almost half the persons have another psychotropic drug prescription at initiation, a quarter have two other drugs and $15 \%$ have three. $40 \%$ of these drugs are antidepressants which is in accordance with a recent publication that warned against the effects of joined drugs [22].

Some limitations should be acknowledged. First, we did not have access to diagnostic information for every patient. This would have allowed us to better specify the context in which medications were prescribed. Those for whom we had a diagnostic, it was the one registered by the general practitioner who initiated the gratuity of the drugs for long-term disease. In addition, 
the present data focuses on prescription and dispensation patterns and does not examine patients' compliance with AP treatment.

\section{CONCLUSIONS}

In France where the health care system reimburses costs associated with pharmacological treatment of psychiatric disorders, SGAP use seems to be restricted to youth and adult patients with psychiatric disorders and tends to be prescribed by mental health specialists. In contrast, FGAPs seem largely used in patients without psychiatric disorders, mainly in elderly patients and to a lesser extent in middle aged adults and tend to be prescribed by GPs. As a result, and considering the greater number of GPs compared to mental health specialists, FGAPs are more prescribed than SGAPs.

Currently, it is not possible to evaluate whether the French patterns of AP drug use are beneficial to patients as compared to what is done is other countries in which the SGAP/FGAP ratio is considerably higher such as in Australia, New Zealand, Spain, Denmark, Finland, Island, Sweden or the U.S. Although important, such comparisons remain complex considering national specificities of health insurance claims data. Further research is needed to expand our understanding of prescription patterns in France, an endeavor that is in line with the insufficient evaluation research pointed in a recent assessment of the mental health and psychiatric policies [23].

That being said, inappropriate AP use (any generation) through off-label use $[9,2]$ especially among vulnerable populations such as youths and the elderly has been brought to attention as potentially damaging practices [10]. In particular, their usage in nursing homes who care for persons suffering from dementia [24] where they constitute risk for fall, among others [25]. This mainly results from FGAPs being prescribed by GPs who do not have psychiatric training and only have limited exchanges with psychiatrists [26]. Particular attention is therefore needed from the regulatory advisory agencies in order to provide sufficient information and training to prescribers. The recent decision by the French Minister of Health to train each new GP by mandatory internship in psychiatric hospitals is very welcomed [27]. 


\section{ACKNOWLEDGEMENTS}

The authors acknowledge the Deniker Foundation, which supported the study, and the French institute of data, which allowed us access to the EGB database.

Legal declaration to the Institut des Données de Santé on the $16^{\text {th }}$ September 2016, approved on the $1^{\text {st }}$ December 2016. 


\section{REFERENCES}

1. Pincus H.A., Tanielian T.L., Marcus S.C., Olfson M., Zarin D.A., Thompson J. et al. Prescribing trends in psychotropic medications: primary care, psychiatry, and other medical specialties. JAMA. (1998) 279 526-531.

2. Verdoux H., Tournier M., Begaud B. Antipsychotic prescribing trends: a review of pharmaco-epidemiological studies. Acta Psychiatr. Scand. (2010) 121 4-10.

3. Geddes J., Freemantle N., Harrison P., Bebbington P. Atypical antipsychotics in the treatment of schizophrenia: systematic overview and meta-regression analysis. BMJ. (2000) 321 1371-1376.

4. Zimmerman M., Ruggero C.J., Chelminski I., Young D. Is bipolar disorder overdiagnosed? J. Clin. Psychiatry. (2008) 69 935-940.

5. Olfson M., Blanco C., Liu L., Moreno C., Laje G. National trends in the outpatient treatment of children and adolescents with antipsychotic drugs. Arch. Gen. Psychiatry. (2006) 63 679-685.

6. Dewa C.S., Remington G., Herrmann N., Fearnley J., Goering P. How much are atypical antipsychotic agents being used, and do they reach the populations who need them? A Canadian experience. Clin. Ther. (2002) 24 1466-1476.

7. Lindesay J., Matthews R., Jagger C. Factors associated with antipsychotic drug use in residential care: changes between 1990 and 1997. Int. J. Geriatr. Psychiatry. (2003) 18 511-519. 8. Halfdanarson O., Zoega H., Aagaard L., Bernardo M., Brandt L., Fuste A.C. et al. International trends in antipsychotic use: A study in 16 countries, 2005-2014. Eur. Neuropsychopharmacol. (2017) 27 1064-1076.

9. Désaméricq G., Schürhoff F., Macquin-Mavier I., Bachoud-Lévi A.-C., Maison P. Use of Antipsychotics: A Study from the French National Insurance Healthcare System Database. Pharmacology \& Pharmacy. (2015) 6411.

10. Verdoux H., Pambrun E., Cortaredona S., Tournier M., Verger P. Antipsychotic prescribing in youths: a French community-based study from 2006 to 2013. Eur. Child Adolesc. Psychiatry. (2015) 24 1181-1191.

11. Bezin J., Duong M., Lassalle R., Droz C., Pariente A., Blin P. et al. The national healthcare system claims databases in France, SNIIRAM and EGB: Powerful tools for pharmacoepidemiology. Pharmacoepidemiol. Drug Saf. (2017) 26 954-962. 
12. Gallini A., Donohue J. M., Huskamp H.A. Diffusion of Antipsychotics in the U.S. and French Markets, 1998-2008. Psychiatric Services. (2013) 64 680-687.

13. Verdoux H., Pambrun E., Tournier M., Bezin J., Pariente A. Antipsychotic long-acting injections: A community-based study from 2007 to 2014 of prescribing trends and characteristics associated with initiation. Schizophr. Res. (2016) 178 58-63.

14. Verdoux H., Pambrun E., Tournier M., Bezin J., Pariente A. Risk of discontinuation of antipsychotic long-acting injections vs. oral antipsychotics in real-life prescribing practice: a community-based study. Acta Psychiatr. Scand. (2017) 135 429-438.

15. H.A.S. 2007 [Available from: https://www.hassante.fr/portail/upload/docs/application/pdf/guide_ald23_schizophr_juin_07.pdf.

16. H.A.S. 2012 [Available from: https://www.has-sante.fr/portail/jcms/c_937781/fr/prise-aulong-cours-d-hypnotiques-anxiolytiques.

17. Prescrire. "Neuroleptiques : trop banalisés" Prescrire. (2016) 36855.

18. H.A.S. 2011 [Available from: https://www.has-

sante.fr/portail/upload/docs/application/pdf/2012-04/anti_psychotiques_rapport.pdf.

19. SC S. The Complete Drug Reference. 35th Edition. . 35th Revised edition ed. London: 2006.

20. HAS. REFERENTIEL DE CERTIFICATION De l'activité d'information par démarchage ou prospection visant à la promotion des médicaments 2017 [Available from: https://www.hassante.fr/portail/upload/docs/application/pdf/2017-

04/dir3/referentiel_de_certification_ip_mars_2017.pdf.

21. C.O.M. Atlas de la démographie médicale 2015 [Available from: https://www.conseilnational.medecin.fr/sites/default/files/atlas_national_de_la_demographie_medicale_2015.pdf. 22. Verdoux H., Pambrun E., Tournier M., Cortaredona S., Verger P. Multi-trajectories of antidepressant and antipsychotic use: a 11-year naturalistic study in a community-based sample. Acta Psychiatr.Scand. (2019) 139 536-547.

23. HCSP. Évaluation du plan psychiatrie et santé mentale 2011-2015 . Paris France; 2016.

24. Nijk R.M., Zuidema S.U., Koopmans R.T. Prevalence and correlates of psychotropic drug use in Dutch nursing-home patients with dementia. Int. Psychogeriatr. (2009) 21 485-493. 
25. Woolcott J.C., Richardson K.J., Wiens M.O., Patel B., Marin J., Khan K.M. et al. Metaanalysis of the impact of 9 medication classes on falls in elderly persons. Arch. Intern. Med. (2009) 169 1952-1960.

26. Kovess-Masfety V., Alonso J., Brugha T.S., Angermeyer M.C., Haro J.M., Sevilla-Dedieu C. et al. Differences in lifetime use of services for mental health problems in six European countries. Psychiatr. Serv. (2007) 58 213-220.

27. Buzyn A. Il faut préserver les moyens de la psychiatrie. Le monde. 2018(26/01/2018). 
Table 1. Initial AP prescription (2013-2014) by gender and age

\begin{tabular}{|c|c|c|c|c|c|c|c|c|c|}
\hline \multirow[b]{2}{*}{ Gender } & \multirow[b]{2}{*}{ AP Generation } & \multicolumn{2}{|c|}{$<18$ years } & \multicolumn{2}{|c|}{18 to $<65$ years } & \multicolumn{2}{|c|}{65 and over } & \multicolumn{2}{|c|}{ Total } \\
\hline & & $\mathbf{N}$ & $\%$ & $\mathbf{N}$ & $\%$ & $\mathbf{N}$ & $\%$ & $\mathbf{N}$ & $\%$ \\
\hline \multirow{3}{*}{ Men } & FGAP & 76 & 24.9 & 989 & 29.2 & 539 & 24.1 & 1604 & 27.0 \\
\hline & FGAP \& SGAP & 3 & 1.0 & 92 & 2.7 & 5 & 0.2 & 100 & 1.7 \\
\hline & SGAP & 123 & 40.3 & 603 & 17.8 & 320 & 14.3 & 1046 & 17.6 \\
\hline \multirow{3}{*}{ Women } & FGAP & 56 & 18.4 & 987 & 29.1 & 795 & 35.5 & 1838 & 31.0 \\
\hline & FGAP \& SGAP & 6 & 2.0 & 46 & 1.4 & 17 & 0.8 & 69 & 1.2 \\
\hline & SGAP & 41 & 13.4 & 672 & 19.8 & 565 & 25.2 & 1278 & 21.5 \\
\hline \multirow{3}{*}{ Overall } & FGAP & 132 & 43.3 & 1976 & 58.3 & 1334 & 59.5 & 3442 & 58.0 \\
\hline & FGAP \& SGAP & 9 & 3.0 & 138 & 4.1 & 22 & 1.0 & 169 & 2.9 \\
\hline & SGAP & 164 & 53.8 & 1275 & 37.6 & 885 & 39.5 & 2324 & 39.1 \\
\hline Total & & 305 & & 3389 & & 2241 & & 5935 & 100.0 \\
\hline
\end{tabular}

AP: Antipsychotic

FGAP: First-generation antipsychotics

SGAP: Second-generation antipsychotics 
Table 2. Breakdown of the most frequent AP drugs reimbursed at initial prescription.

Bold names concern SGAPs.

\begin{tabular}{|c|c|}
\hline Drug & Rate (\%) \\
\hline CYAMEMAZINE & 22.55 \\
\hline RISPERIDONE & $\mathbf{2 1 . 4 5}$ \\
\hline TIAPRIDE & 11.36 \\
\hline SULPIRIDE & 8.82 \\
\hline HALOPERIDOL & 6.96 \\
\hline ARIPIPRAZOLE & $\mathbf{5 . 4 4}$ \\
\hline QUETIAPINE & $\mathbf{5 . 2 3}$ \\
\hline OLANZAPINE & $\mathbf{5 . 0 4}$ \\
\hline LOXAPINE & 3.08 \\
\hline CHLORPROMAZINE & 3.01 \\
\hline AMISULPRIDE & 2.36 \\
\hline LEVOMEPROMAZINE & 1.87 \\
\hline
\end{tabular}


AP: Antipsychotic

SGAP: Second-generation antipsychotics 
Table 3a. Number of prescriptions with concomitant reimbursement of AP and non-AP psychotropic drugs

\begin{tabular}{|c|c|c|c|c|c|c|c|c|c|c|c|c|c|c|}
\hline \multirow{3}{*}{ Generation } & \multicolumn{14}{|c|}{ Number of concomitant reimbursed drug } \\
\hline & \multicolumn{2}{|c|}{0} & \multicolumn{2}{|c|}{1} & \multicolumn{2}{|c|}{2} & \multicolumn{2}{|c|}{3} & \multicolumn{2}{|c|}{4} & \multicolumn{2}{|c|}{5} & \multicolumn{2}{|c|}{6} \\
\hline & $\mathrm{N}$ & $\%$ & $\mathrm{~N}$ & $\%$ & $\mathrm{~N}$ & $\%$ & $\mathrm{~N}$ & $\%$ & $\mathrm{~N}$ & $\%$ & $\mathrm{~N}$ & $\%$ & $\mathrm{~N}$ & $\%$ \\
\hline FGAP & 1793 & 52.1 & 862 & 25.0 & 505 & 14.7 & 220 & 6.4 & 50 & 1.5 & 12 & 0.3 & & . \\
\hline FGAP \& SGAP & 54 & 32.0 & 66 & 39.1 & 29 & 17.2 & 16 & 9.5 & 2 & 1.2 & 2 & 1.2 & . & . \\
\hline SGAP & 1079 & 46.4 & 640 & 27.5 & 382 & 16.4 & 183 & 7.9 & 31 & 1.3 & 6 & 0.3 & 3 & 0.1 \\
\hline Average & 2926 & 49.3 & 1568 & 26.4 & 916 & 15.4 & 419 & 7.1 & 83 & 1.4 & 20 & 0.3 & 3 & 0.1 \\
\hline
\end{tabular}


AP: Antipsychotic

FGAP: First-generation antipsychotics

SGAP: Second-generation antipsychotics 
Table 3b. Nature of prescriptions with concomitant reimbursement of AP and non-AP psychotropic drugs

\begin{tabular}{|c|c|c|}
\hline ATC classification & Frequency & $\%$ \\
\hline PSYCHOANALEPTICS & 1782 & 43.09 \\
\hline PSYCHOLEPTICS & 2354 & 56.91 \\
\hline
\end{tabular}

AP: Antipsychotic 
Table 4. Type of AP prescriber according to AP generation and age.

\begin{tabular}{|c|c|c|c|c|c|c|c|c|c|c|c|c|}
\hline & \multicolumn{3}{|c|}{ HOSPITAL-BASED PRACTITIONNER } & \multicolumn{3}{|c|}{ GENERAL PRACTITIONNER } & \multicolumn{3}{|c|}{ PSY/NEURO. PRACTITIONNER } & \multicolumn{3}{|c|}{ ALL PRACTITIONNERS } \\
\hline & $\mathbf{N}$ & $\begin{array}{c}\text { Between } \\
\text { generation } \\
\text { comparison } \\
\text { (\%) }\end{array}$ & $\begin{array}{c}\text { Within } \\
\text { generation } \\
\text { (\%) }\end{array}$ & $\mathbf{N}$ & $\begin{array}{c}\text { Between } \\
\text { generation } \\
\text { comparison } \\
\text { (\%) }\end{array}$ & $\begin{array}{c}\text { Within } \\
\text { generation } \\
\text { (\%) }\end{array}$ & $\mathbf{N}$ & $\begin{array}{c}\text { Between } \\
\text { generation } \\
\text { comparison } \\
\text { (\%) }\end{array}$ & $\begin{array}{c}\text { Within } \\
\text { generation } \\
\text { (\%) }\end{array}$ & $\mathbf{N}$ & $\begin{array}{c}\text { Between } \\
\text { generation } \\
\text { comparison } \\
\text { (\%) }\end{array}$ & $\begin{array}{c}\text { Within } \\
\text { generation } \\
\text { (\%) }\end{array}$ \\
\hline \multicolumn{13}{|c|}{ All age groups } \\
\hline FGAP & 819 & 49.4 & 23.8 & 1965 & 69.3 & 57.1 & 433 & 40 & 12.6 & 3442 & 58 & 100 \\
\hline FGAP \& SGAP & 97 & 5.9 & 57.4 & 27 & 1.0 & 16 & 36 & 3.3 & 21.3 & 169 & 2.8 & 100 \\
\hline SGAP & 742 & 44.8 & 31.9 & 844 & 29.8 & 36.3 & 613 & 56.7 & 26.4 & 2324 & 39.2 & 100 \\
\hline Total & 1658 & 100 & 27.9 & 2836 & 100 & 47.8 & 1082 & 100 & 18.2 & 5935 & 100 & 100 \\
\hline \multicolumn{13}{|c|}{$<18$ years } \\
\hline FGAP & 69 & 41.6 & 52.3 & 33 & 55.9 & 25 & 19 & 30.6 & 14.4 & 132 & 43.3 & 100 \\
\hline FGAP \& SGAP & 5 & 3.0 & 55.6 & 1 & 1.7 & 11.1 & 3 & 4.8 & 33.3 & 9 & 3.0 & 100 \\
\hline SGAP & 92 & 55.4 & 56.1 & 25 & 42.4 & 15.2 & 40 & 64.5 & 24.4 & 164 & 53.8 & 100 \\
\hline Total & 166 & 100 & 54.4 & 59 & 100 & 19.3 & 62 & 100 & 20.3 & 305 & 100 & 100 \\
\hline \multicolumn{13}{|c|}{18 to $<65$ years } \\
\hline FGAP & 512 & 49.2 & 25.9 & 979 & 75.7 & 49.5 & 355 & 41 & 18 & 1976 & 58.3 & 100 \\
\hline FGAP \& SGAP & 83 & 8.0 & 60.1 & 18 & 1.4 & 13 & 31 & 3.6 & 22.5 & 138 & 4.1 & 100 \\
\hline SGAP & 445 & 42.8 & 34.9 & 296 & 22.9 & 23.2 & 480 & 55.4 & 37.6 & 1275 & 37.6 & 100 \\
\hline Total & 1040 & 100 & 30.7 & 1293 & 100 & 38.2 & 866 & 100 & 25.6 & 3389 & 100 & 100 \\
\hline \multicolumn{13}{|c|}{$\geq 65$ years } \\
\hline FGAP & 238 & 52.7 & 17.8 & 953 & 64.2 & 71.4 & 59 & 38.3 & 4.4 & 1334 & 59.5 & 100 \\
\hline
\end{tabular}




\begin{tabular}{cccc|ccc|ccc|ccc} 
FGAP \& SGAP & 9 & 2.0 & 40.9 & 8 & 0.5 & 36.4 & 2 & 1.3 & 9.1 & 22 & 1.0 & 100 \\
SGAP & 205 & 45.4 & 23.2 & 523 & 35.2 & 59.1 & 93 & 60.4 & 10.5 & 885 & 39.5 & 100 \\
Total & 452 & 100 & 20.2 & 1484 & 100 & 66.2 & 154 & 100 & 6.9 & 2241 & 100 & 100 \\
\hline
\end{tabular}

AP: Antipsychotic

FGAP: First-generation antipsychotics

SGAP: Second-generation antipsychotics 
Table 5. Main diagnoses related to AP prescription in the context of ALD allowance $(n=2255)^{*}$.

\begin{tabular}{|c|c|c|c|c|c|c|c|c|}
\hline & & & & LD diagnos & & & & \\
\hline & $\begin{array}{c}\text { Substance use } \\
\text { disorders }\end{array}$ & Schizophrenia & $\begin{array}{c}\text { Depression } \\
\text { (excl. bipolar) }\end{array}$ & $\begin{array}{l}\text { Bipolar } \\
\text { disorders }\end{array}$ & Anxiety & $\begin{array}{c}\text { Mental } \\
\text { retardation }\end{array}$ & Autism & Dementia \\
\hline $\mathrm{N}(\%)$ & $137(6.1)$ & 257 (11.4) & 764 (33.9) & $228(10.1)$ & $74(3.3)$ & $69(3.1)$ & $60(2.7)$ & 666 (29.5) \\
\hline AP genera & akdown (\%) & & & & & & & \\
\hline FGAP & $70.1^{*}$ & $38.5^{*}$ & $55.5^{*}$ & $32.9 *$ & $60.8^{*}$ & 42.0 & $30.0^{*}$ & 49.0 \\
\hline SGAP & $29.9 *$ & $61.5^{*}$ & $44.5 *$ & $67.1^{*}$ & $39.2^{*}$ & 58.0 & $70.0 *$ & 51.1 \\
\hline
\end{tabular}

* Among patients who had an ALD allowance that could be related to a psychiatric diagnosis $(n=2458)$ minus those with psychiatric diagnoses too rare to be pooled (203 cases)

AP: Antipsychotic

FGAP: First-generation antipsychotics

SGAP: Second-generation antipsychotics

ALD: Affection Longue Durée - Long-term illness 
Figure 1 : year 2015 prevalence by age and gender for FGAP and SGAP per 1000 persons

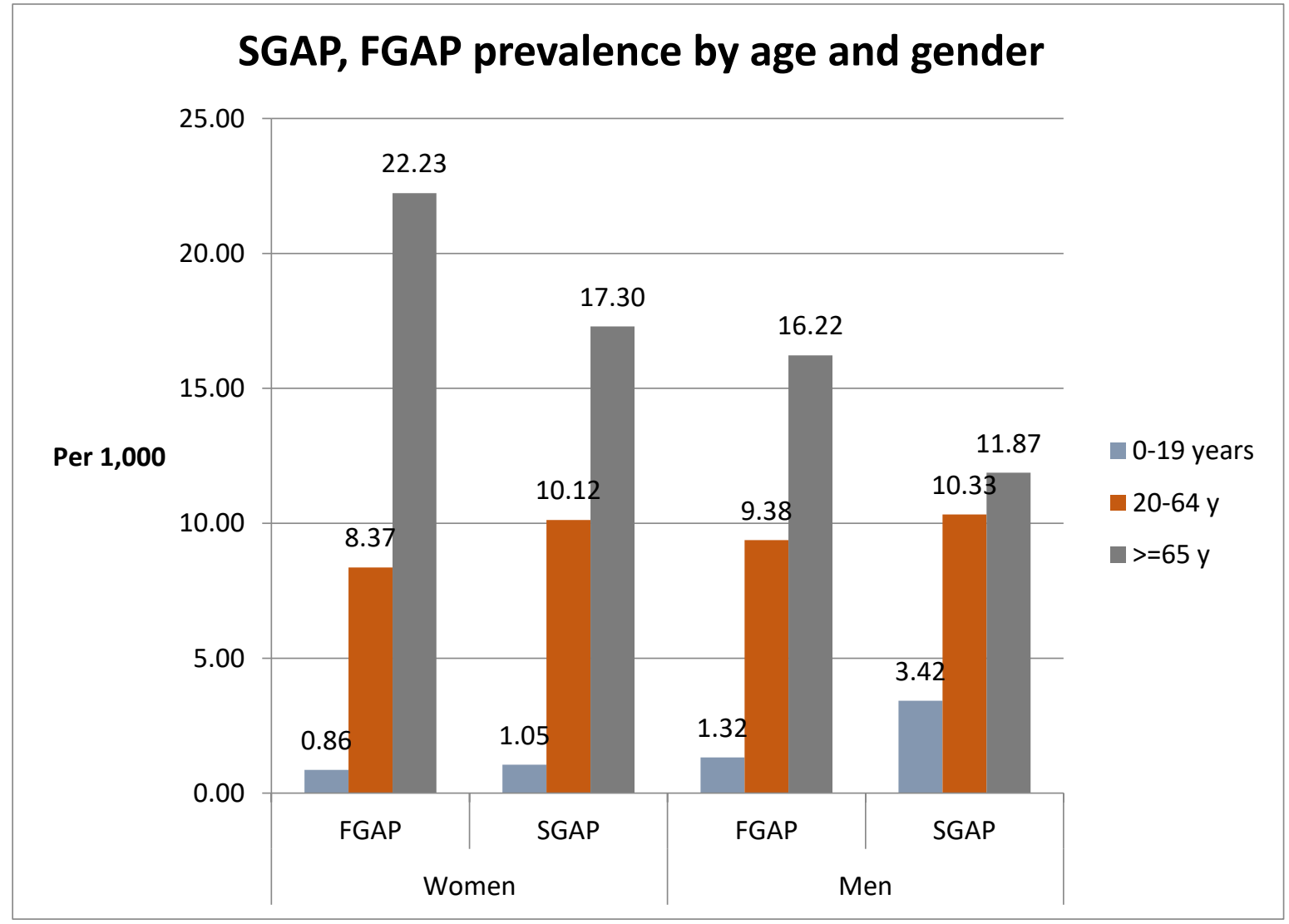

FGAP: First-generation antipsychotics

SGAP: Second-generation antipsychotics 
Figure 2

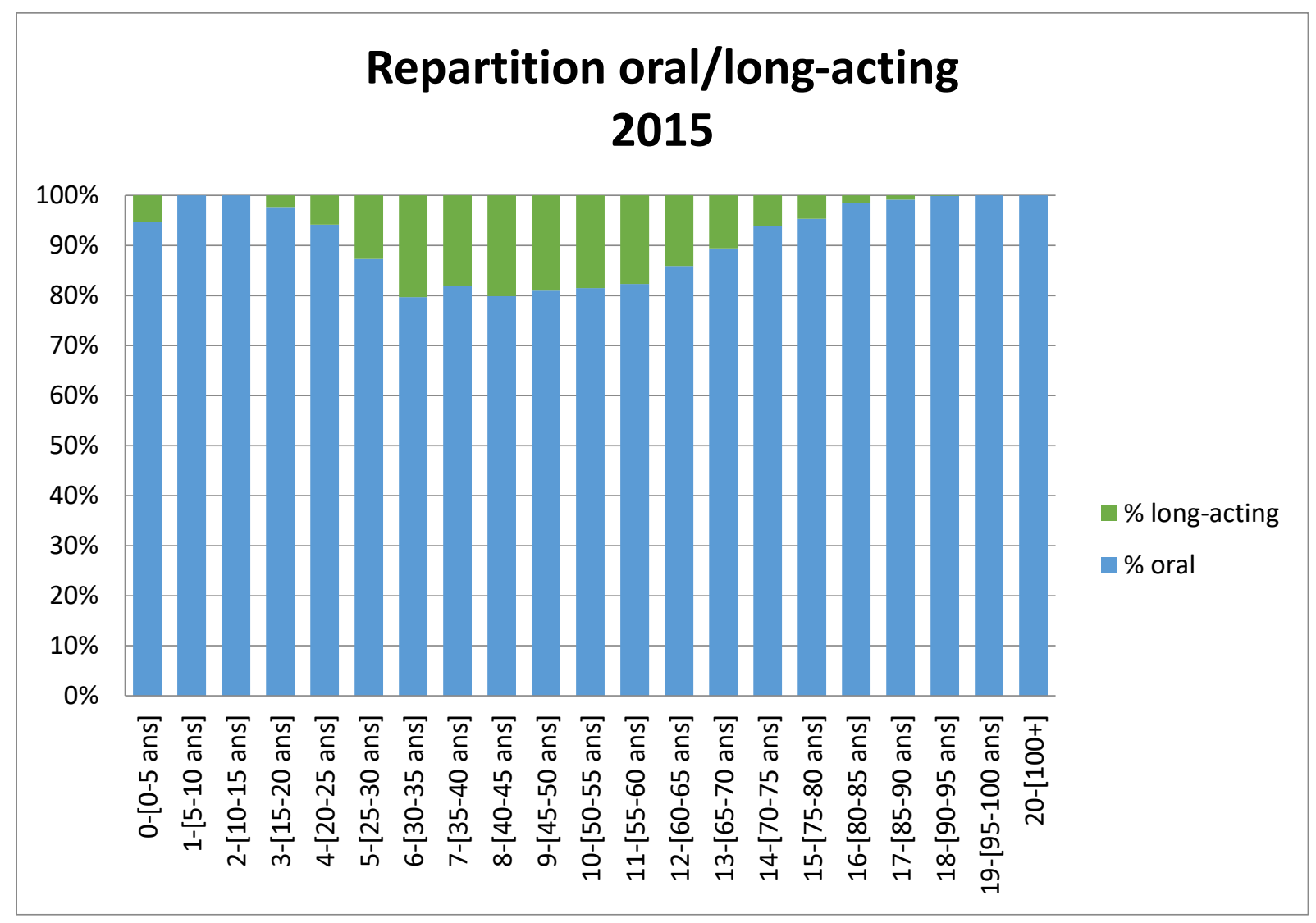

